\title{
Light and electron microscope appearances in renal biopsy material from cases of recurrent haematuria in children
}

\author{
R. LANNIGAN AND J. INSLEY \\ From the Department of Pathology, University of Birmingham, \\ and the Birmingham Children's Hospital
}

Recurrent attacks of haematuria in children create a difficult diagnostic problem. After elimination of a lower urinary tract source of the haemorrhage, renal tuberculosis, and haemorrhagic diseases, there remains an ill-defined group of cases in which the source of the haemorrhage is believed to be in the glomerulus or tubule. Most of the previous work on this group of cases has either been clinical without pathological observations or the pathological studies have been made after death. Renal biopsy has now, however, permitted the examination of renal tissues during life and this communication deals with the light and electron microscopic appearances of renal biopsy material from five cases of recurrent haematuria selected from a larger series.

\section{CLINICAL INVESTIGATIONS}

Intravenous pyelograms, obtained in four of the children when they first attended hospital and in case 1 before renal biopsy, were normal. Cytoscopy was carried out only in case 5 and showed nothing abnormal. All the children had negative 1/1,000 intradermal Mantoux skin tests and normal chest radiographs. The deposits from early morning urines obtained from all but case 1 were examined by Ziehl-Neelson stain, cultured on Lowenstein-Jensen medium, and inoculated into guineapigs. All the tests were negative for tuberculosis.

Urinary tract infection was excluded by repeated urine cultures and colony counts. (Colony counts were determined from mid-stream specimens after serial dilution in $0.9 \%$ saline and culture on blood agar and McConkey's medium.) There was no growth in four cases while in case 4 there were 6,300 colonies per millilitre. Since this was a mixed growth it was not considered significant. Blood obtained from the renal biopsy needle in cases 2 and 5 and cultured in Liquoid $(0.3 \%$ sodium polyanetholsulphonate) was sterile. Platelet counts were made and bleeding and clotting times determined during an attack of haematuria and before renal biopsy. All were within normal limits. The

Received for publication 28 April 1964. presence and quantity of urinary protein was estimated with salicylsulphonic acid and the centrifuged deposit examined for cells and casts. A micro modification of the Wintrobe method was used to determine the E.S.R.

\section{RENAL FUNCTION}

This was assessed by blood urea and creatinine clearance estimations. The clearances were determined on isolated four-hourly collections of urine and corrected for body size (Peters and Van Slyke, 1932).

\section{RENAL BIOPSY}

The biopsies were carried according to the method of Muehrcke, Kark, and Piraní (1955). The tissue was divided and one part fixed in formol-sublimate for light microscopy. Paraffin sections were cut at $2-4 \mu$ and stained with haematoxylin and eosin, Van Gieson, the periodicacid-Schiff method, and the periodic-acid silver method. The second part was fixed in $1 \%$ buffered osmium tetroxide for electron microscopy. The glomeruli were located by cutting $1 \mu$ serial sections. Ultra-thin sections were cut on a Huxley ultramicrotome and examined in a Siemens series 6 electron microscope.

CASE 1 This boy, age 6 years, developed painless haematuria, oliguria, and slight facial oedema 18 days after the onset of an upper respiratory infection. A group A type 2 haemolytic streptococcus was isolated from the throat. The urine contained more than $100 \mathrm{mg}$. protein per $100 \mathrm{ml}$., large numbers of R.B.C.s, a few W.B.C.s, granular and cellular casts. The blood urea was $46 \mathrm{mg}$. per $100 \mathrm{ml}$. and the E.S.R. was $38 \mathrm{~mm}$. in the first hour. He was treated with penicillin and after three weeks diuresis occurred and the blood chemistry returned to normal. The urine still contained a trace of protein and a few R.B.C.s. Two months after the original attack he developed pyrexia with a sore throat and haematuria but no oliguria or oedema. Streptococci were not isolated. He was treated with tetracycline and penicillin and two weeks later he had another attack of haematuria. Right renal biopsy was carried out two weeks later. Tonsillectomy was performed and no further relapses occurred during the next two years. 


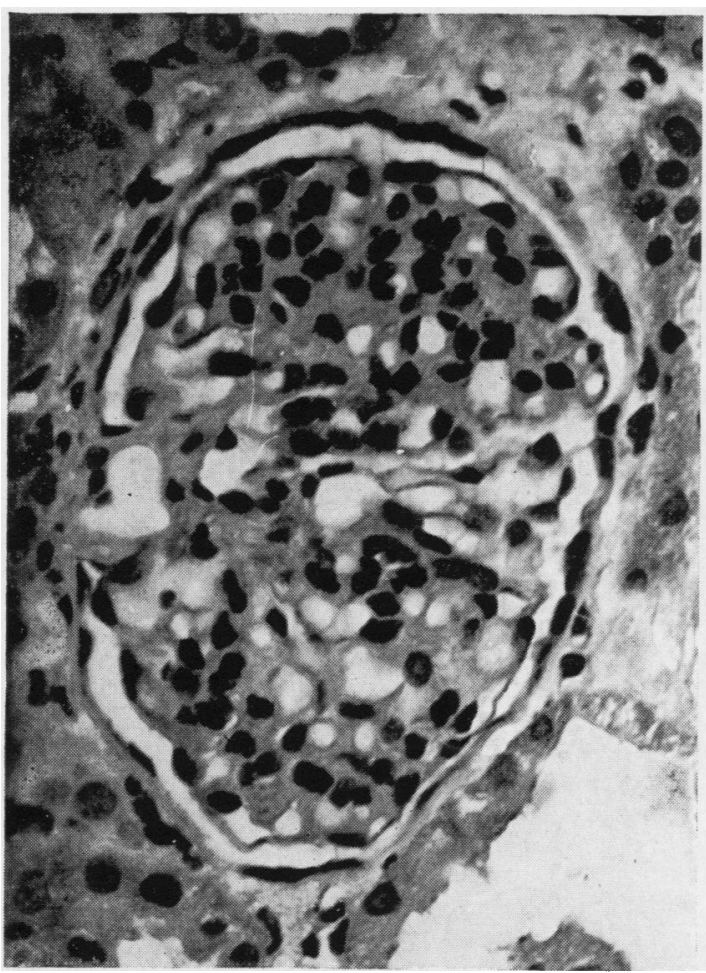

FIG. 1. Focal areas of cellular proliferation associated with a fibrillary deposit in the axial zones in case 1. Haematoxylin and eosin $\times 520$.
Light microscopy Focal areas of cellular proliferation, probably endothelial or axial, are present (Fig. 1) in some glomeruli while others are normal. With the P.A.S. and P.A. silver methods these focal areas are seen to be associated with increased P.A.S.-positive and silverpositive material in the axial zones. The basement membrane proper does not appear to be thickened. Occasional glomeruli show capsular adhesions but there are no crescents. The other renal elements show no abnormality.

Electron microscopy The electron microscopic findings are variable from glomerulus to glomerulus and in different areas of the same glomerulus.

The capillary basement membrane measured at various areas in peripheral open loops varied in thickness from 1,800 to $5,000^{\circ} \mathrm{A}$. (Fig. 2) (upper limit of normal in the adult $3,000^{\circ} \mathrm{A}$ ). Towards the axial zones the membrane was frequently folded and thickened. The inner edge of the membrane was often scalloped and irregular in appearance. The thickening was fairly uniform in individual loops and did not show areas of differing electron density. Endothelial and axial cells were increased in number and the cytoplasm contained numerous large clear vacuoles. The foot process layer was well preserved but there were small areas of fusion. Bowman's capsule was not thickened.

CASE 2 This girl, age $4 \frac{1}{2}$ years, had blood in a single specimen of urine seven days after an indefinite illness associated with mild diarrhoea. Two days later two further isolated specimens of urine contained blood and she was admitted to hospital. There were no abnormal physical signs and, apart from a trace of protein, R.B.C.s, W.B.C.s, granular and cellular casts in the urine, all

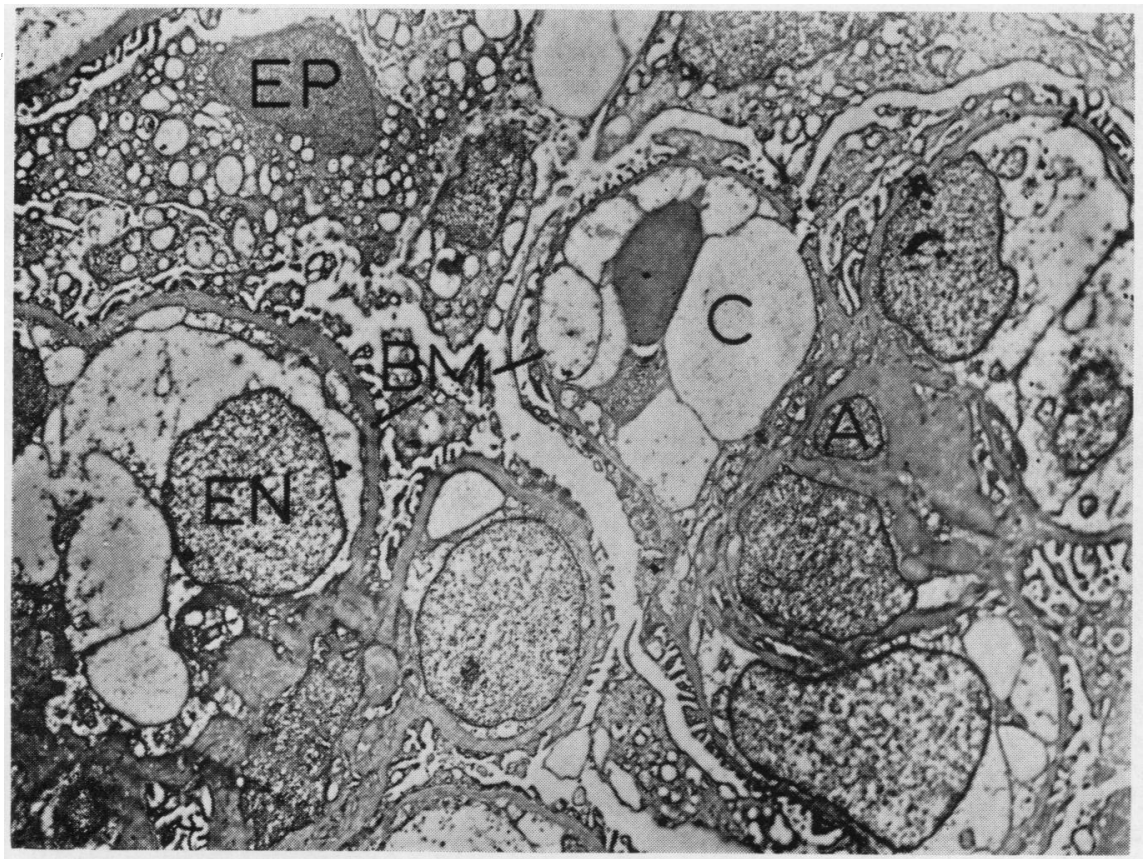

FIG. 2. Low-power view of glomerulus showing a marked difference in thickness of basement membrane and increase in hasement-membranelike material in axial zone in case 1. Osmic methacrylate $\times 5,000$.

In all illustrations: $A=$ axial cell; $B M=$ basement membrane; $C=$ capillary lumen; $E N=$ endothelial cell; $E P=$ epithelial cell; $F P=$ foot process; $R B C=$ red blood cell. 


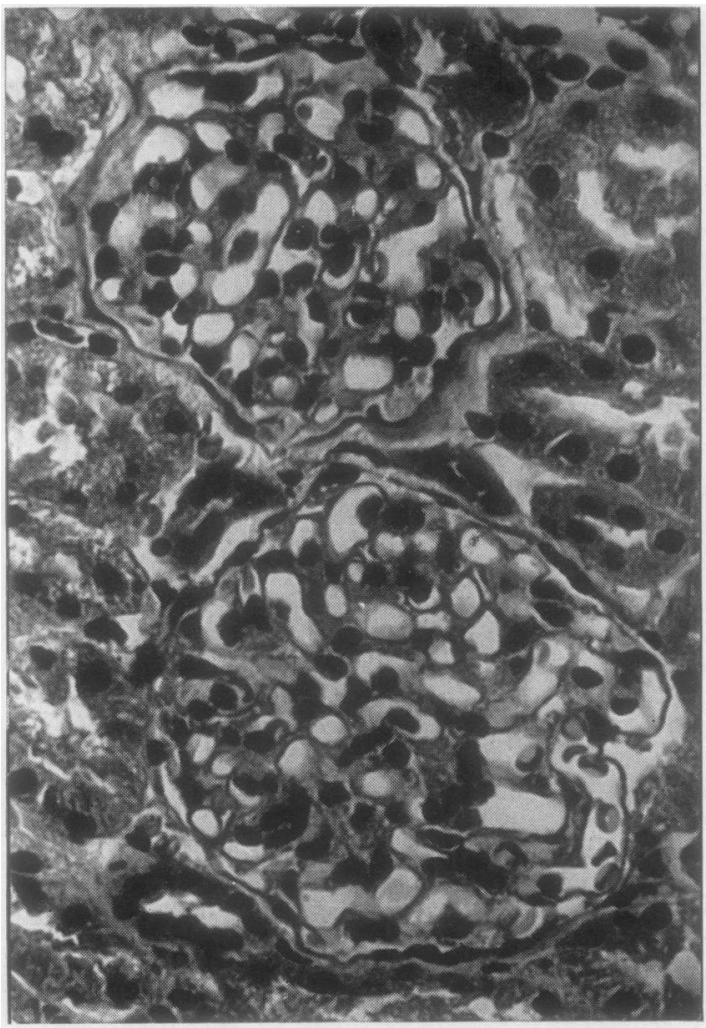

FIG. 3. In the axial zones there are fibrillary deposits of P.A.S.-positive material (case 2). P.A.S. $\times 520$.

other investigations were negative. She was treated empirically with sulphonamide. Further attacks of haematuria occurred after discharge from hospital and she was confined to bed since it was noted that haematuria occurred when she got up. She was re-admitted after six months following such an attack. Apart from blood and casts in the urine all investigations were again negative. Renal biopsy was performed and culture of the needle blood was sterile. Over the next year haematuria recurred but with diminishing frequency.

Light microscopy There are few or no cellular proliferative changes in the glomeruli. The main lesion consists of thickening of the axial zones in some glomeruli with material which is P.A.S.- and P.A.-silver positive (Fig. 3). One glomerulus shows capsular adhesions.

Electron microscopy In one of the glomeruli studied there is a distinct increase in epithelial cells in some parts (Fig. 4). In the other three glomeruli examined no proliferative changes were noted. The basement membrane shows variations in thickness in peripheral loops varying from $1,100^{\circ} \mathrm{A}$ to $4,750 \mathrm{~A}^{\circ}$ and towards some axial zones are markedly thickened and folded. In some areas there is a deposit of material in the axial zones resembling basement membrane in relation to axial and endothelial cells. This material is arranged in spurs or rounded clumps and continuity with basement membrane can be seen in places.

The endothelial and axial cells are not increased in number and the cytoplasm appears normal.

The epithelial cells are normal apart from the one glomerulus where there is an increase. The foot process layer is well preserved. Occasional protein absorption droplets are found in epithelial cell cytoplasm.

In the glomerulus showing epithelial cell proliferation there is a deposit of electron dense material. In several areas it is closely applied to the outer (epithelial) side of the basement membrane and is found in Bowman's space (Fig. 4). In one other area it is found in the axial zone closely applied to the inner surface of the basement membrane (Fig. 5). This material resembles that described by Farquhar, Vernier, and Good (1957) as fibrinoid.

CASE 3 A girl, aged 6 years, had her first attack of haematuria following an attack of otitis media. Several other attacks during the next two and a half years were unrelated to upper respiratory infections, time of day, or exercise. During one attack the blood pressure, E.S.R., and blood urea were normal. Between attacks the urine was clear or contained traces of protein and occasional R.B.C.s. Two and a half years after the onset and shortly after such an attack right renal biopsy was performed. At this time all clinical investigations were negative. The urine was sterile and contained less than $100 \mathrm{mg}$. per $100 \mathrm{ml}$. protein with a moderate number of red cells. The child had several attacks of haematuria in the six months following biopsy.

Light microscopy Focal glomerular lesions with areas of capillary collapse and axial thickening are present, cellular proliferative changes being minimal. Occasional glomerular adhesions are noted but no crescents. There is a marked increase of P.A.S.- and P.A.-silver-positive material in the axial zones in some glomeruli and thickening of basement membrane is seen in some loops (Fig. 6).

Electron microscopy The basement membrane shows considerable variation in thickness in open loops the range being 1,900 to $5,250^{\circ} \mathrm{A}$.

Focal areas of capillary collapse are seen and in the axial zones there is an accumulation of basement membrane-like material, sometimes in large quantities. The membrane in the axial zones is sometimes markedly folded and thickened (Fig. 7). The endothelial and axial cells are increased in number in some areas but show no other changes. Apart from large clear vacuoles, the epithelial cells show no special features. The foot process layer is preserved.

CASE 4 This girl, aged 6, had a first attack of haematuria without oliguria or oedema three months after otitis media. An erythematous rash on the buttocks had been present immediately after the attack of otitis media. On admission six weeks after the onset of haematuria a group A streptococcus was isolated from the throat and the antistreptolysin $O$ titre was 333 Todd units. The urine contained $100 \mathrm{mg}$. protein per $100 \mathrm{ml}$., R.B.C.s, and occasional W.B.C.s and casts. All other investigations were negative. Renal biopsy was performed four months 


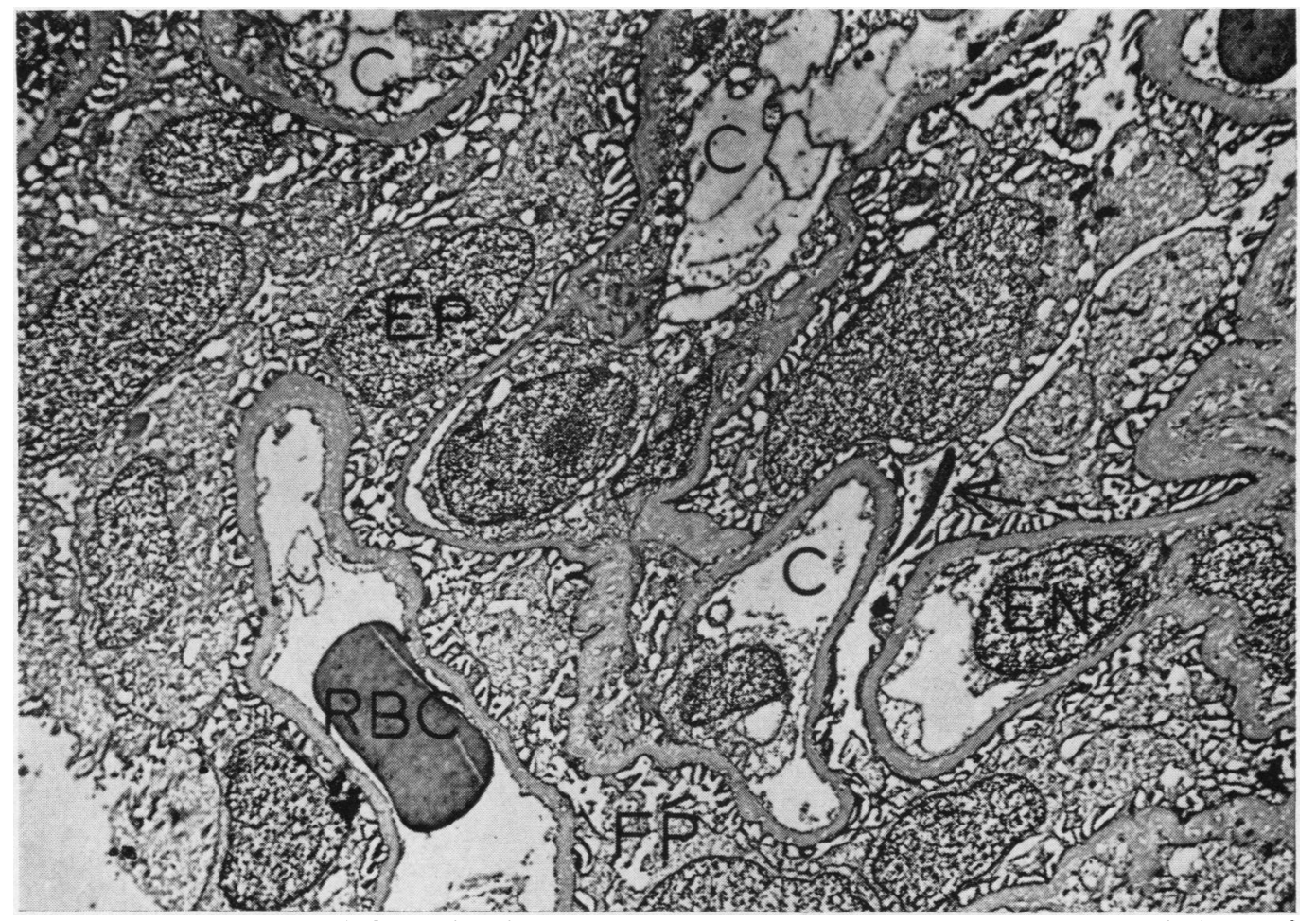

FIG. 4. Low-power view of glomerulus showing increase in epithelial cells and variation in the thickness of peripheral basement membrane in case 2. In Bowman's space there is an osmiophilic deposit (arrow) which continues on to the outer surface of the basement membrane. Osmic methacrylate $\times 4,000$.

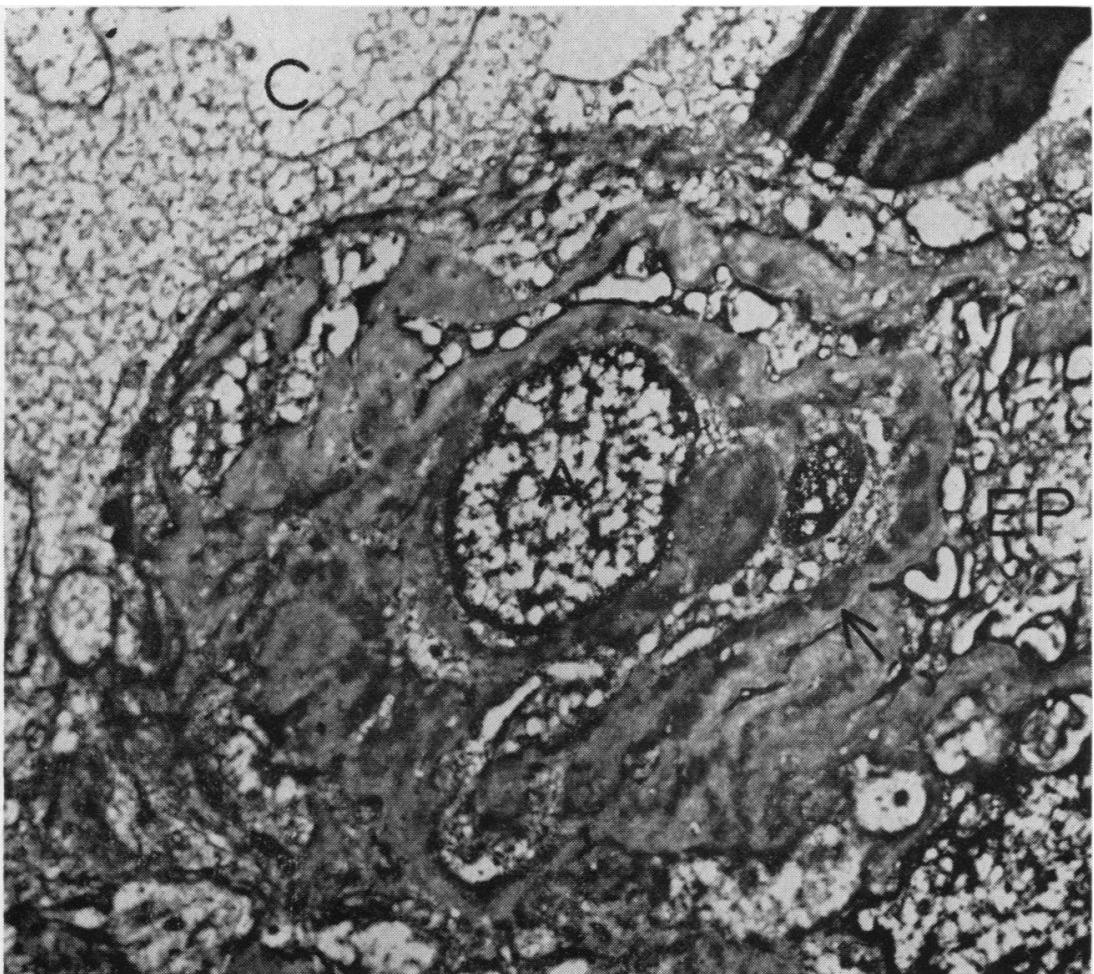

FIG 5. Axial zone showing a layer of osmiophilic material (arrow) in relation to the inner surface of the basement membrane (case 2). Osmic methacrylate $\times 8,500$. 


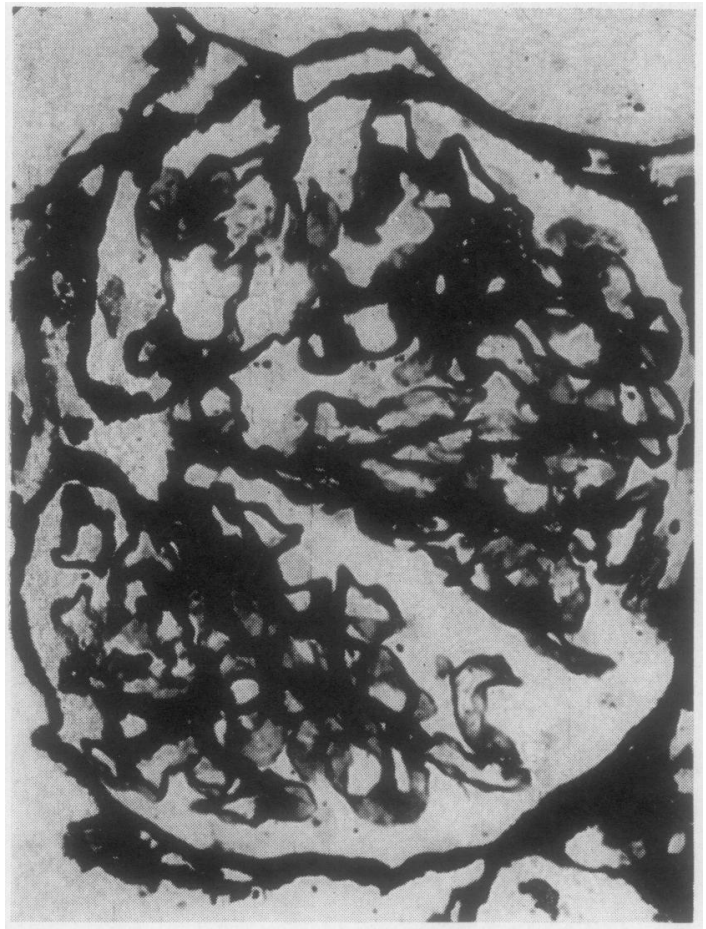

FIG. 6. Glomerulus showing deposition of P.A.-silverpositive material in the axial zones in case 3 . In some capillaries the basememt membranes are thickened.P.A.silver $\times 520$.

FIG. 7. Marked thickening and folding of basement membrane and increase in basement membrane-like material in axial zones in case 3. Osmic methacrylate $\times 8,500$.

FIG. 6

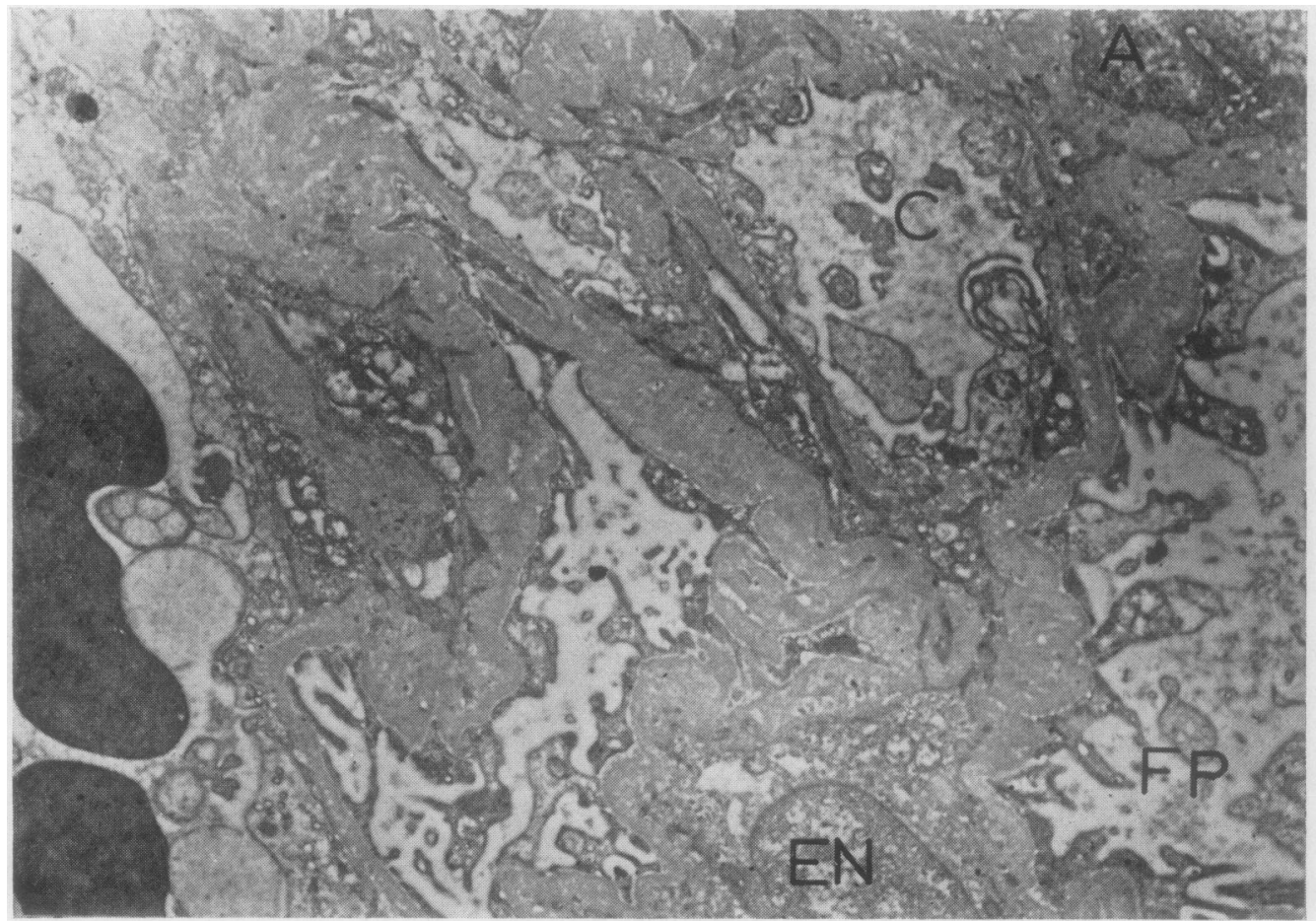

FIG. 7 


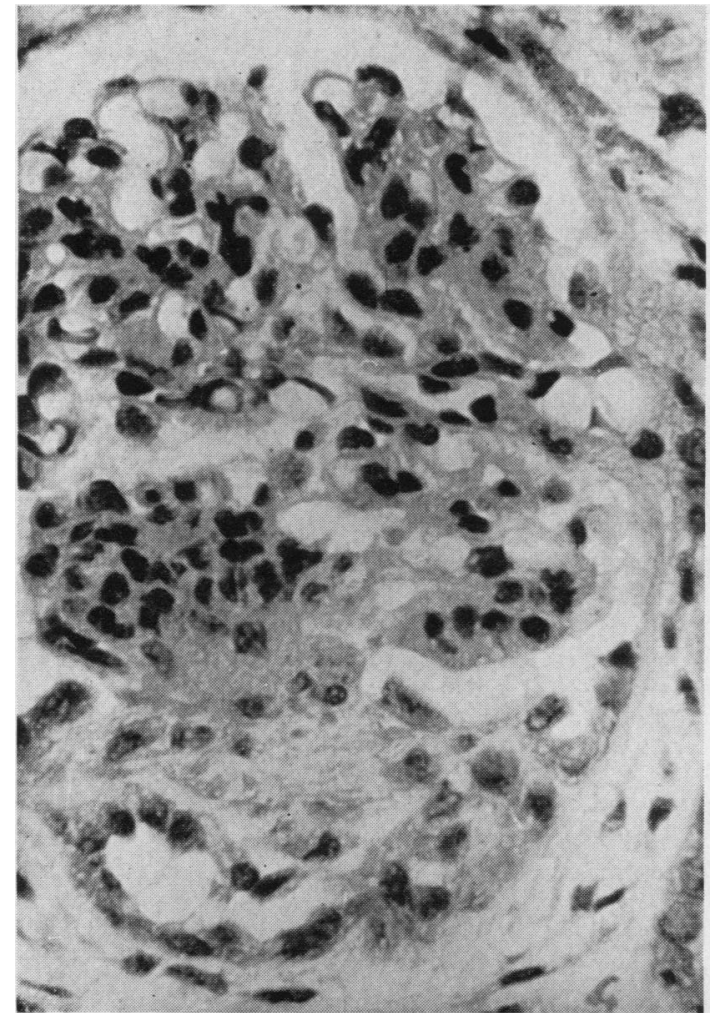

after the onset of haematuria. Since biopsy attacks have continued. Some have been precipitated by other respiratory infections and last about one day. Between attacks the urine contains traces of protein, R.B.C.s, and occasional casts.

Light microscopy Focal glomerular lesions were found sometimes with areas of cellular proliferation but in other areas there was an increase in P.A.S. and P.A. silver material in the axial regions (Fig. 8). Glomerular adhesions were found but not crescents. Some glomeruli were undamaged. Red blood cells were found in some tubules.

Electron microscopy Some areas of endothelial and axial cell proliferation were noted but the epithelial cells appeared normal. The foot process layer was preserved in most areas.

The basement membrane did not show any marked degree of thickening but in the axial zones in relation to the proliferated endothelial and axial cells there were deposits of basement membrane-like material (Fig. 9). In one glomerulus a red blood cell was noted in Bowman's space and red blood cells were present in one distal tubule.

FIG. 8. Glomerulus showing focal cellular proliferation associated with a fibrillury deposit in case 4. Glomerular adhesions are present. Haematoxylin and eosin $\times 520$.

FIG. 9. Centrilobular zone with axial and endothelial cell proliferation in case 4 . Note the deposits of basement membrane-like material. Osmic methacrylate $\times 8,750$.

FIG. 8

FIG. 9

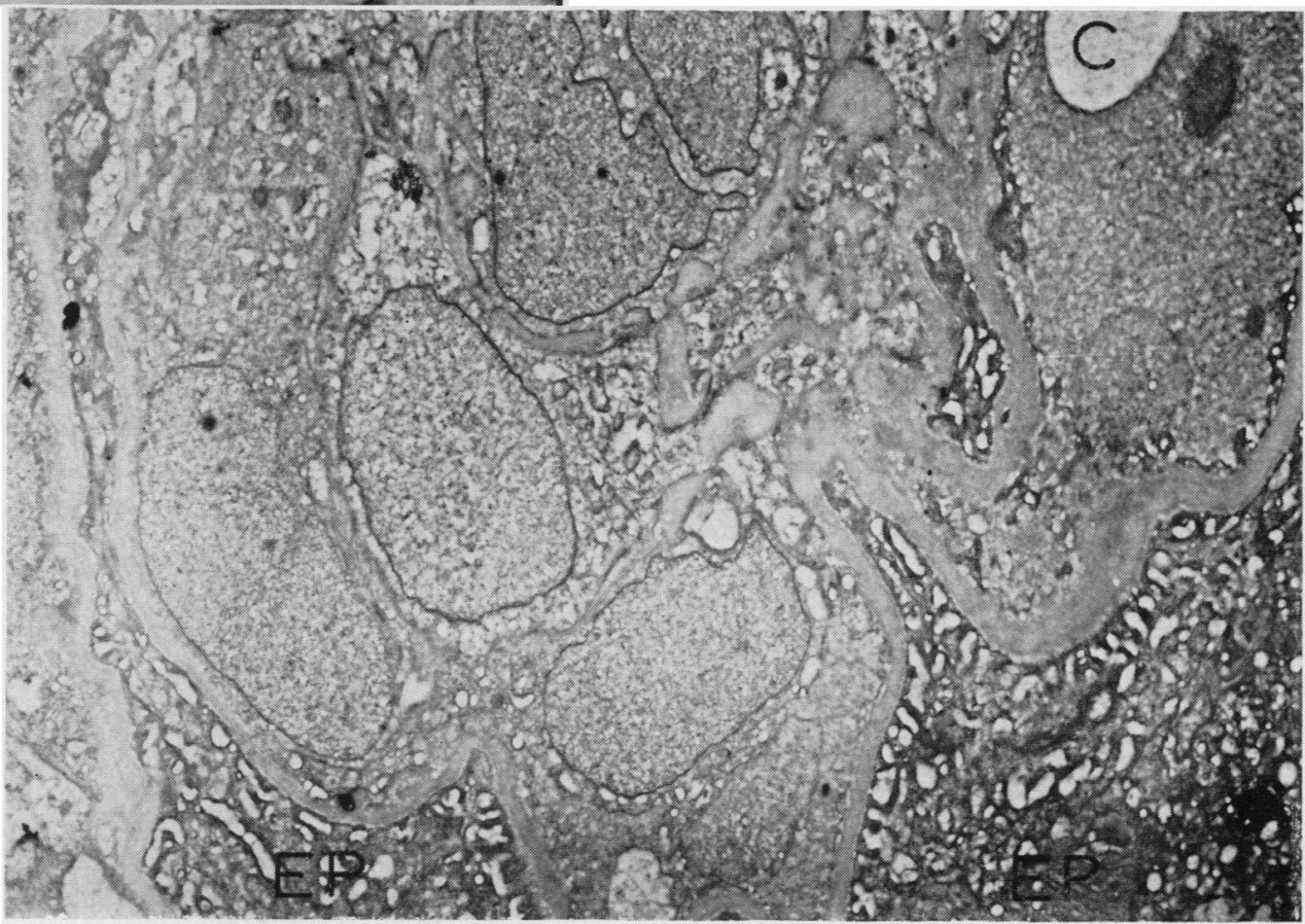




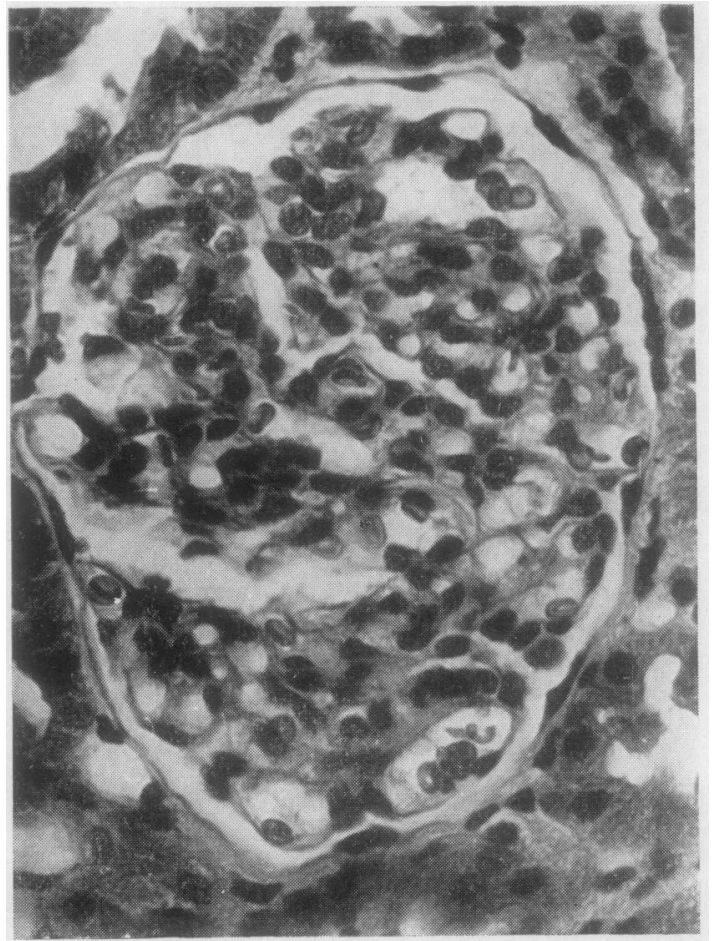

FIG. 10. Glomerulus showing small areas of crowding of nuclei with deposition of fibrillary material in some of the axial zones in case 5. Haematoxylin and eosin $\times 520$.
CASE 5 A boy at age of $4 \frac{1}{2}$ years had an upper respiratory infection. Two and a half weeks later, after two days' vomiting, he had an attack of haematuria and this recurred four times in the next week. There was no oliguria or oedema. He was seen four weeks after the onset of haematuria when the urine contained a trace of protein with moderate numbers of R.B.C.s. Other investigations were negative. Further bouts of haematuria occurred over the next few months. One of these appeared a few days after tonsillitis but most were precipitated by exercise. On admission 10 months after the onset of haematuria, the urine was free of protein and cells. The creatinine clearance was $66 \mathrm{ml}$. per minute per 1.73 square metre body surface area. Renal biopsy was performed 11 months after the onset of haematuria. Since biopsy he has had slight macroscopic haematuria following an upper respiratory tract infection.

Light microscopy The glomerular changes were focal in nature and not very pronounced. The most prominent feature is crowding of nuclei in small areas, capillary collapse, and areas of deposition of fibrillary material in the axial zones (Fig. 10).

Electron microscopy There is a striking difference in thickness of basement membrane in open peripheral loops. The membranes range from approximately $1,000^{\circ} \mathrm{A}$ to $4,000^{\circ} \mathrm{A}$ and in the axial zones are thickened and folded. Strands and irregular masses of basement membrane-like material are present in the axial zones (Fig. 11). In the glomeruli examined there was no increase of endothelial or axial cells. The epithelial cells were not increased in number and the foot process layer was

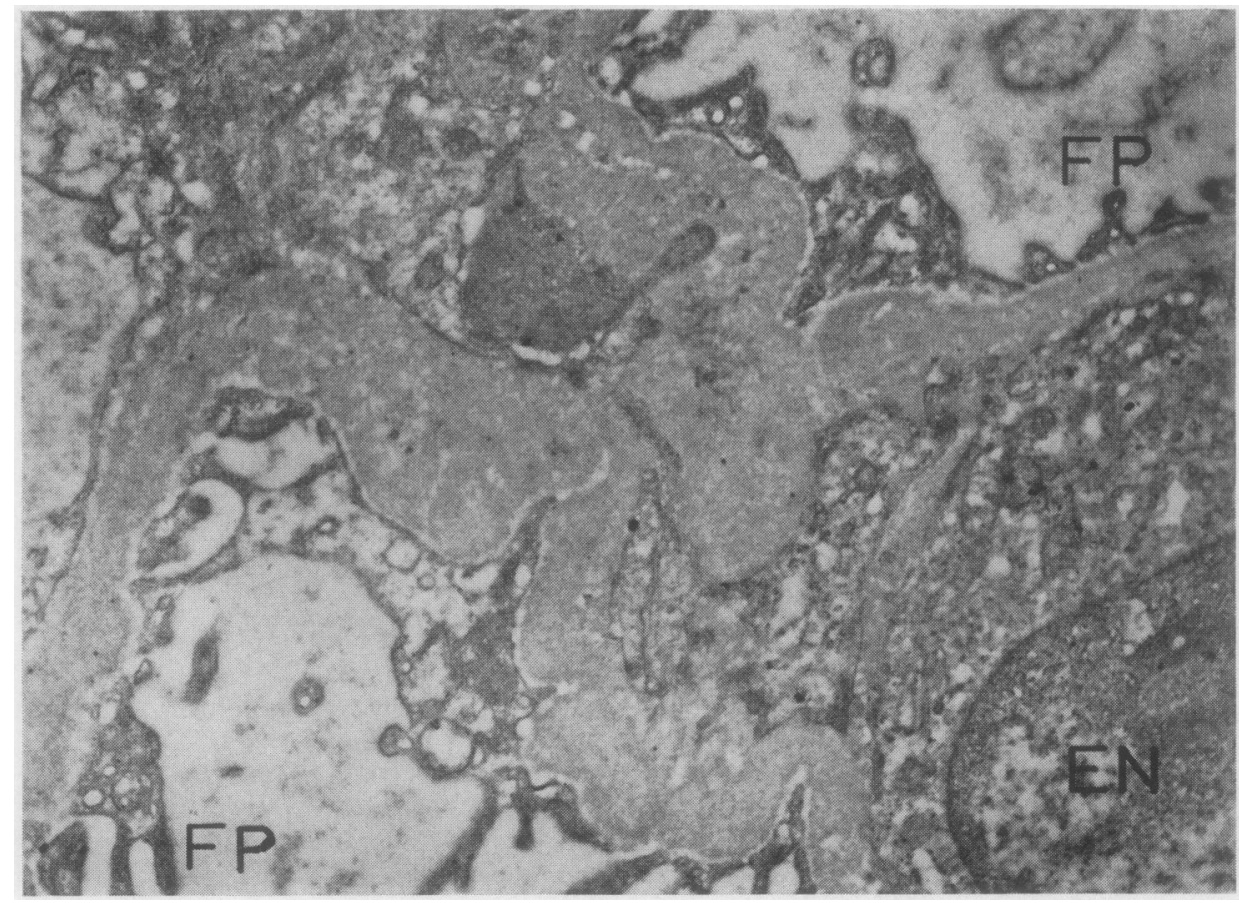

FIG. 11.

Axial zone

showing

marked

folding and

thickening of

the basement

membrane

(case 5).

Osmic

methacrylate

$\times 12,000$. 
generally preserved. In a few capillary loops foot processes had fused.

\section{DISCUSSION}

CLINICAL DIAGNOSIS As far as possible sources of haemorrhage in the urinary tract, especially calculus and hydronephrosis, pyelonephritis, and bleeding diathesis, were excluded by clinical investigations. In three cases the presence of casts at some time in the illness confirmed that the renal substance itself was involved. The differential diagnosis was thought to be between latent glomerulonephritis with recurrences, acute focal nephritis, and other forms of nephritis complicating Henoch-Schonlein purpura and the collagen diseases. Although audiometric testing was not carried out there was no family history of either renal disease or early onset of deafness and this probably excluded hereditary nephritis (Alport, 1927). There was no evidence of collagen diseases although antinuclear factor tests were not carried out. Since there was no history of abdominal pain, swollen painful joints, and skin rashes at the onset of the illness, Henoch-Schonlein purpura was considered unlikely.

There was good evidence, however, that the original illness in case 1 was acute glomerulonephritis following a group $\mathrm{A} \beta$-haemolytic infection and while recovery was taking place there were two exacerbations associated with tonsillitis from which streptococci were not isolated. Recurrences of gross haematuria in glomerulonephritis at the height of an upper respiratory infection and without the re-appearance of oliguria, oedema, or hypertension have previously been well recorded (Winkenwerder, McLeod, and Baker, 1935; Snoke, 1937; Seegal, Lyttle, Loeb, Jost, and Davis, 1940). In cases 3 and 5 the original illness may also have been acute glomerulonephritis as in both there was a latent interval between the upper respiratory infection and the onset of haematuria. Since the urines were usually free of protein and cells between attacks they were considered clinically to be cases of acute focal nephritis (Scheidemandel, 1913; Volhard and Fahr, 1914). Even in these children the illness did not fit well with the classical description of this disease as the haematuria did not first appear at the height of the infection.

The subsequent course of case 4 suggested a progressive glomerulonephritis.

A clinical diagnosis was not hazarded in case 2.

NATURE OF THE LeSIONS Although the lesions are variable from case to case they show some degree of similarity. In all cases the lesions are focal within glomeruli and many glomeruli are spared. In some lesions there is a variable degree of cellular proliferation, mainly endothelial and axial, but occasionally epithelial cells are also increased although crescents and capsular adhesions are not observed.

The significance of the increase in basement membrane-like material in the axial zones in all cases is difficult to evaluate. Similar changes are found in glomerulonephritis (Farquhar et al., 1957; Kimmelstiel, Kim, and Beres, 1962), preeclamptic toxaemia (Pirani, Pollak, Lannigan, and Folli, 1963), diabetes (Bergstrand and Bucht, 1959; Farquhar, Hopper, and Moon, 1959), experimental glomerulonephritis of various types (Robertson and More, 1961; Lannigan, 1963), and other conditions. This change is associated with a wide range of functional disturbances and it is not clear if the material is the same in different diseases. It is not known if it is produced locally or is a deposit from the blood stream organized into material superficially resembling basement membrane. The most striking feature is the variability of basement membrane thickness from loop to loop in four cases. We have insufficient material to give an upper limit of normal thickness in children but many loops are almost twice as thick as those found in adults. In some cases the thin appearance of the membrane in occasional loops was so markedly different from the others that it seems likely that the thin loops are also abnormal although they fall within the normal range for young children. In unaffected glomeruli such thin loops are not seen. Bloom, Hartmann, and Vernier (1959) found the mean width to be $1,100^{\circ} \mathrm{A}$ in young children and $2,700^{\circ} \mathrm{A}$ in older children and adults. The membranes are usually uniform in thickness and do not show areas of differing electron density. A difference in thickness of basement membrane has been noted in early diabetics (Sabour, Macdonald, and Robson, 1962; Lannigan, Blainey, and Brewer, 1964) but the difference in these cases of haematuria is much more striking.

Focal glomerular lesions are found with varying histological appearances in a variety of conditions. These have been variously described as acute focal nephritis, focal glomerulitis, focal glomerulonephritis bacterial nephritis, non-suppurative focal glomerulonephritis, and in the case of subacute bacterial endocarditis have been called focal embolic nephritis. Similar types of lesion are associated with a variety of diseases, including disseminated lupus erythematous and polyarteritis nodosa, and do not provoke a uniform type of urinary disturbance. The group described by Gray (1933) of haematuria occurring at the height of acute infections showed focal glomerular lesions which contained polymorphs. This was interpreted as a bacterial infection of the glomeruli, a view also expressed by Fishberg 
(1954). Allen (1962) lists a great variety of infections, chemical poisons, etc., which are associated with focal glomerular lesions. In the infections he does not believe that organisms are present in the lesions.

Blainey (1961) described haematuria in association with focal pyelonephritis but there was no evidence of this in our cases.

In other renal biopsy series focal glomerulonephritis has been described with differing clinical features. Bates, Jennings, and Earle (1957) described focal glomerular lesions in cases of non-streptococcal glomerulonephritis which are similar to those in our cases. Heptinstall and Joekes (1959) described a group of 13 cases with focal glomerular lesions and nine of these had R.B.C.s in the urine, including three cases of Henoch-Schonlein purpura. Although the lesions described are similar to those in our series the clinical features are different. It is interesting to note that Rusby and Wilson (1960) described focal glomerulonephritis in cases of lung purpura which in later biopsies became diffuse. They suggested that focal glomerulonephritis may be an earlier stage of diffuse glomerulonephritis in various diseases.

The clinical impression of diffuse glomerulonephritis in case 1 and chronic glomerulonephritis in case 3 was not supported by the histological observations. These lesions do not correspond to the generally accepted histological picture of diffuse glomerulonephritis but it is possible that the time interval between the haematuria and the biopsy could have permitted some degree of healing.

SOURCE OF THE HAEMORRHAGE In only one of our cases (case 4) were red blood cells detected in Bowman's space and in tubules. We have been unable to demonstrate breaches of the basement membrane but the electron microscopic appearances indicate an abnormality of the capillary basement membrane. The nature of the damage to glomerular capillaries which permits haemorrhage to take place even in acute diffuse glomerulonephritis is not known. The reparative capacity of the membrane may be very great and following escape of red blood cells, possibly by stretching of a small breach, capillary contraction may occur. Several of our cases showed areas of what we have interpreted as capillary collapse. Earle and Jennings (1960) described a variety of cases of focal glomerulonephritis and in several biopsies from cases of haematuria red blood cells were found in Bowman's space of normal-looking glomeruli. Electron microscope studies were not, however, carried out.

In one of our cases haematuria was provoked by exercise. Illingworth and Holt (1957) described a child who developed haematuria following exercise but histological studies were not carried out and the source of the haemorrhage is not known. Cases of recurrent haematuria associated with pyelovenous backflow have been described in adults (Hinman and Redewill, 1926; Pytel, 1960) but not in children.

In our cases the presence of glomerular lesions makes the glomerulus a likely source of the haemorrhage but does not entirely exclude a tubular source.

\section{CONCLUSIONS}

The histological diagnosis in these cases is focal glomerulitis but this term is in common use not only to indicate focal glomerular lesions but is used to describe a clinical syndrome. Because of the lack of correlation between the presence of focal glomerular lesions and the clinical state it would be better to restrict the term to the pathological findings and to qualify if possible with the type of clinical presentation. The use of the term 'clinically' without pathological verification is no longer justified and leads to confusion. In the present series the description could be 'focal glomerulitis with recurrent haematuria'.

Until the aetiology is known and careful follow-up studies have been carried out, it would be better to postpone final decisions as to the nature of these lesions and their prognosis.

We wish to thank the clinical consultant staff of the Children's Hospital, Birmingham, for clinical data and Dr. A. H. Cameron for the light microscope photographs.

Some financial assistance was received from the Endowment Fund of the United Birmingham Hospitals.

\section{REFERENCES}

Allen, A. C. (1962). The Kidney, 2nd ed., p. 195. Churchill, London. Alport, A. C. (1927). Brit. med. J., 1, 504.

Bates, R. C., Jennings, R. B., and Earle, D. P. (1957). Amer. J. Med., 23, 510 .

Blainey, J. D. (1961). In Ciba Foundation Symposium on Renal Biopsy edited by G. E. W. Wolstenholme and M. P. Cameron, p. 271. Churchill, London.

Bergstrand, A. and Bucht, H. (1959). J. Path. Bact., 77, 231.

Bloom, P. M., Hartmann, J. F., and Vernier, R. L. (1959). Anat. Rec., 133, 251 .

Earle, D. P., and Jennings, R. B. (1960). Trans. Amer. clin. Climat. Ass., 72, 24.

Farquhar, M. G., Hopper, J., Jr., and Moon, H. D. (1959). Amer. J. Path., 35, 721.

- Vernier, R. L., and Good, R. A. (1957). J. exp. Med., 106, 649.

Fishberg, A. M. (1954). Hypertension and Nephritis, p. 654. Baillière, London.

Gray, J. (1933). A Study of Nephritis and Allied Lesions. Spec. Rep. Ser. med. Res. Coun. (Lond.), 178.

Heptinstall, R. H., and Joekes, A. M. (1959). Quart. J. Med., 28, 329.

Hinman, F., and Redewill, F. H. (1926). J. Amer. med. Ass., 87, 1287

Illingworth, R. S., and Holt, K. S. (1957). Arch. Dis. Childh., 32, 254.

Kimmelstiel, P., Kim, O. J., and Beres, J. (1962). Amer. J. clin. Path., 38, 280.

Lannigan, R. (1963). Brit. J. exp. Path., 44, 326. 
—, Blainey, J. D., and Brewer, D. B. (1964). J. Path. Bact., 88, 255. Muehrcke, R. C., Kark, R. M., and Pirani, C. L. (1955). J. Urol. (Baltimore), 74, 267.

Peters, J. P., and Van Slyke, D. D. (1932). Quantitative Clinical Chemistry, p. 569, vol. 2, Methods. Baillière, London.

Pirani, C. L., Pollak, V. E., Lannigan, R., and Folli, G. (1963). Amer. J. Obst., Gyn., 87, 1047.

Pytel, A. (1960). J. Urol. (Baltimore), 83, 783.

Robertson, D. M., and More, R. H. (1961). Arch. Path., 72, 331.

Rusby, N. L., and Wilson, C. (1960). Quart. J. Med., 29, 501.
Sabour, M. S., Macdonald, Mary K., and Robson, J. S. (1962). Diabetes, 11, 291.

Scheidemandel, E. (1913). Münch. med. Wschr., 60, 1778.

Seegal, D., Lyttle, J. D., Loeb, E. N., Jost, E. L., and Davis, G. (1940). J. clin. Invest., 19, 569.

Snoke, A. W. (1937). Amer. J. Dis. Child., 53, 673.

Volhard, F., and Fahr, T. (1914). Die Bright'sche Nierenkrankheit. Springer, Berlin.

Winkenwerder, W. L., McLeod, N., and Baker, M. (1935). Arch. intern. Med., 56, 297.

\section{The January 1965 Issue}

\section{THE JANUARY 1965 ISSUE CONTAINS THE FOLLOWING PAPERS}

Report on antibiotic sensitivy test trial organized by the Bacteriology Committee of the Association of Clinical Pathologists

The cleaning of instruments and syringes E. M. DARMADY, K. E. A. HUGHES, S. E. DREWETT, D. PRINCE, WINIFRED TUKE, and PATRICIA VERDON

Hair as a reservoir of staphylococci MARGARET $M$. SUMMERS, P. F. LYNCH, and T. BLACK

Studies on the dispersal of staphylococci W. C. NOBLE and R. R. DAVIES

An outbreak of meningitis associated with E.C.H.O virus type 9 C. R. NEWMAN and R. B. F. SMITH

Prophylaxis against tetanus: An investigation into efficiency of a method M. LAURENCE, L. B. HOLT, C. E. GRAHAM, and G. L. W. BONNEY

Preparation and use of fixative slides for the diagnosis of Trichomonas vaginalis C. R. AMIES and MARIA GARABEDIAN

Cytological diagnosis of breast tumours by the imprint method C. R. TRIBE

Intramural ganglia in diverticular disease of the colon W. A. A. G. MACBETH and J. H. R. HAWTHORNE

Diagnostic problems in biliary duct lymph nodes GEORGE WILLIAMS and J. S. WHITTAKER

Exudative lesions in diabetes mellitus G. I. HORSFIELD and R. LANNIGAN

\section{Congenital neuroblastoma A. R. EVANS}

Electron microscopy of a rhabdomyosarcoma of the ear I. FRIEDMAN, D. F. N. HARRISON, W. N. TUCKER, and E. S. BIRD
Some aspects of calcium metabolism in malignant disease of bone M. G. RINSLER, MYFANWY GWYTHER, and E. $O$. FIELD

Variability in the water, sodium, and potassium, and chloride content of human skeletal muscle C. T. G. FLEAR, R. G. CARPENTER, and IRENÉ FLORENCE

Clinical value of the cortisol secretion rate c. L. COPE and J. PEARSON

Differential ferrioxamine test for measuring chelatable body iron J. FIELDING

Method for the automatic determination of serum iron D. S. YOUNG and JOCELYN M. HICKS

Influence of iron preparations on occult blood tests D. G. ILLINGWORTH

Quantitative separation of radioactive sterols and bile acids in human faeces B. LEWIS and N. B. MYANT

Anaemia in occult intestinal malabsorption R. WHITEHEAD, R. L. CARTER, and A. A. SHARP

Diagnostic value of serum haptoglobin N. K. SHINTON, R. W. RICHARDSON, and J. D. F. WILLIAMS

The direct antiglobulin (Coombs) test in megaloblastic anaemia J. FORSHAW and LILIAN HARWOOD

Association of Clinical Pathologists: 73rd general meeting

\section{Technical methods}

Chromosome analysis from human skin N. P. BISHUN, M. N. RASHAD, and W. R. M. MORTON

Turbidimetric method for the determination of serum globulin using the AutoAnalyzer J. H. GLENN

Book reviews

Copies are still available and may be obtained from the PUBLISHING MANAGER, BRITISH MEDICAL ASSOCIATION, TAVISTOCK SQUARE, W.C.I., price 18s. 6D. 